\title{
The necessity for management of common subjects and quality as- surance for higher education of mastery of skills by using qualify- ing examinations in university Liberal Arts classes
}

\author{
Katsuichi Higuchi*
}

\begin{abstract}
We discuss quality assurance for education content and evaluation of mastery of skills by using qualifying examinations in university Liberal Arts classes. It is considered that there are three merits in using those examinations: 'Clarity of degree of achievement and evaluation criteria', 'Easy management for multiple classes', and 'Encouraging students' learning motivation'. Then we show a case of teaching qualifying examinations in information literacy classes as an example of quality assurance of education at a college.

Keywords: quality assurance, qualifying examination, certification, license
\end{abstract}

\section{Introduction}

Recently in Japan, it must be noted that quality assurance in higher education is absolutely necessary [1]. In kindergartens, elementary schools, junior high schools, and high school, the classes are conducted in accordance with the course of study [2] specified by government. These students are taught by teachers who completed teacher-training courses certified by government and have licenses for each school. Therefore we may say that the education content of classes in these schools is assured in quality. On the other hand, in higher education institutes, for example, in the case of universities, teachers don't always have teaching licenses and there are no clear curriculum guidelines because it has been hoped in general that university students learn academic contents proactively and then researchers rather than teachers teach students academic contents at their own discretion. That is, there is no system to assure quality for the education content of classes in the institutes. In Japan, however, because of the popularization of universities caused by declining the birthrate, all students who register for universities don't necessarily want to study academic content. It is considered that the number of students who want to study academic content is decreasing.

In this situation, the education of basic literacy ability, for example, information literacy, remedial education, or first-year experience, has been carried out for university students. Many researches about such education have also carried out. So, generic content is more important than academic one and as a result, it becomes easy to assure quality of education content and evaluation of study in classes. In order to realize such assurance, the management of multiple classes is acquired by full-time teachers and administrators.

In addition, the rate of students who are interested in licenses or qualifying examinations (qualifying exams) is more and more increasing. Then a lot of universities have been publicizing their courses of qualification and teaching programs for qualifying exams. Here, a term,

\footnotetext{
* Institute of Liberal Arts, Otemon Gakuin University, Osaka, Japan
} 
'license', may be classified in three categories as 'license and certification', 'title', and 'qualifying exam' [3].

- License and certification to have a monopoly business: Ex. Doctor, nurse, lawyer, etc...

- Title: Ex. BA, MA, PhD, etc...

- Qualifying examination to prove the skill : Ex. TOEFL, TOEIC, etc...

In previous studies, surveys on teaching licenses or qualifying exams at universities and junior colleges in Japan had been carried out [4], and it was pointed out that there were merits on teaching qualifying exams in university classes $[5,6]$. We insist on three advantages in it: 'Clarify of goals', 'Easy management for multiple classes', and 'Encouraging students' learning motivation'.

In this study, we are going to consider acquire of management for multiple classes and using qualifying exams for quality assurance of education content and evaluation of study in liberal arts classes at universities.

This paper is organized as follows. In next section, we discuss the necessity of management for above generic subjects in Liberal Arts (L.A.). Then, we propose three merits on using qualifying examinations in university classes in Sec. 3. In Sec. 4, we show a case in the information literacy classes using them, and analyze the effect of using qualifying examinations for students' learning motivation. The survey result of student preference about qualifying exams is presented in Sec. 5. Sec. 6 is devoted for a summary.

\section{The necessity for management of common subjects in order to achieve quality assurance of education}

In this section we will discuss the management of classes in institute of common subjects in the L.A. of universities including junior colleges and vocational schools. We believe that the curriculum such as tuition outlines to be submitted to the Ministry of Education, Culture, Sports, Science and Technology is created on a full discussion in each university. On the other hand, we estimate that the management such as the coordination between class personnel may not be carried out with the same kind of prudence as when creating the curriculum in order to run it reliably. In that case, even if the curriculum is designed to have a connection between the subjects, the classes may not be carried out systematically. In reality, for example, the each teaching personnel often don't know the textbook, the class level, or the student learning achievement of the other classes handled by other instructors.

We give some examples of such failure.

1. When the curriculum is designed for students to take B subject after the study of A subject,

(1) the instructor in charge of B begins to teach higher than what they learn in A.

(2) the expression method and the degree of difficulty of a text for B is different from that for A's.

(3) the ways of tuition of A is different from that of B.

We often see the above cases. Although it is clear that the case (1) is a problem, some instructors insist that the case (2) or (3) is no problem because they think personality and expertise of the instructor are important. However, when we put myself in the student's shoes, (1) is of course a problem and (2) or (3) is also considered as a problem. It is better for students that expression of the B's text is the same as A's like the series of the publishing company same as text of A and B ((2)). It is also better that the way of tuition such as the performance evaluation, the quiz, the term-end exam, and the appearance of handouts (font size, font, expression method of header and footer, etc.) are the same in common subjects ((3)).

Furthermore,

2. when several classes in the same subject are offered,

(4) each syllabus is different.

(5) each text is different. 
(6) each performance evaluation method is different.

(7) the way of each teaching is different.

Unfortunately, the above fours may also be regard with no problem. However, when we put myself in the student's shoes, we think these are problems in the view of quality assurance and fairness of the education.

From the above discussion, we conclude that it should be unified about above (1)-(7) for students. Though, various difficulties will occur to carry it out even if it is one of the unifications. We tried to give those difficulty cases as follows.

A. Lack of awareness between faculty members that should unify above (1)-(7)

B. Absence of the post which gathers or full-time instructors in charge

C. Lack of opportunities and time of the meeting for the teaching personnel. The meeting time is limited, especially in case of teaching personnel is part-time instructor.

D. Opinion to oppose the unification as the "Course content and methods should leave to the instructor," or "Those should be put out as their own color of the instructor."

The A-D is shown in order to be resolved.

First, for resolving A, discussions with faculty members having opinion of $\mathrm{D}$ may not often lead to agreement, and that may only exhaust us. Therefore it should be forced by the aid of top-down.

For resolving B, the post which gathers should be academic affairs office and the person who gathers should be the full-time faculty professor or lecturer in charge of the class. The duty of the full-time faculty professor or lecturer is including not only teaching and research, but also the management of several classes. At first, full-time faculty members in charge determine contents about (4)-(7) in each class, they should carry out the management of such description and adjustment to other instructors in charge of the class.

For $\mathrm{C}$, however it takes much time and much effort to start a unifying initially, those labor will decrease if manuals are completed.

For $\mathrm{D}$, it is difficult to persuade people who have such an opinion. If the lesson contents and teaching methods are falling apart in each faculty, they may insist that "because students learn carefully in these difficult situations, students get to force to learn more than in furnished situation." In other words, students gain power as study in the situation that it is hard to learn. However the opinion was true for students who enrolled in universities before the times when university admission capacity exceeds the 18-year-old population (we call the situation "university all incoming times") [7], and it is true for students who pass the entrance examination of universities training a high-level researcher, it is not true for students who enroll in normal-level universities after the times. Because we admit a lot of students who don't have sufficient basic academic skills, we have to perform lessons as they can understand. In all incoming times, in the universities of the normal-level except the universities of high quality, it may be difficult for almost students to understand the class in L.A. including many academic contents $[8,9,10]$.

From above discussion we are going to focus on the necessity for management of computer literacy classes offered from institute of L. A.in following.

In a lot of universities, introductory classes to learn computer literacy are set up in the first year. The subject name is as "Introduction of computer", "Information literacy", or "Basic computer" etc. They are set up as one year course, or as a half year course like "Introduction of computer 1 or 2." In general, the goal of these subjects is acquisition of basic knowledge and skills to use a personal computer rather than learning of academic information knowledge and skills. In particular, the details are

1. the basic knowledge of information, such as ethics and computer networks, and

2. the skills for using office software (MS Word, MS Excel MS PowerPoint).

As for the goal of two above, the originality of the instructors in charge is not found in the 
academic knowledge and skill and contents. The goal is an indeed so-called "standard content" which almost office worker think as. The standard content should not be one which the instructors originally consider as standard. If each instructor freely teaches students the standard content which he originally plans, the student who took "Introduction computer 1 (A class)" and the student who take "Introduction computer 1 (B class) may learn different contents unfortunately. The standard content should be unified to things used in the general business spot.

And then we suggest 5 tasks for standardization of education as follows.

A. Standardization of syllabus

B. Standardization of progress

C. Adoption of unified text

D. Unification of the distribution print

E. Standardization of teaching methods

Indeed above five standardization lead to quality assurance of education. Furthermore, we will suggest that we use qualifying examinations $[11,12]$ to realize standardization of the education in the following sections.

\section{Merits on the use of qualifying exams in University classes}

We think there are three merits in using qualifying exams for university education. They are as follows, 'Clarify of goals and evaluation criteria', 'Easy management for multiple classes', and 'Encouraging students' learning motivation'. Hence, this method seems useful in view of quality assurance for education content and evaluation of study in university classes.

\subsection{Clarify of goals and evaluation criteria}

Goals and contents of most of the qualifying exams are explicitly declared. Then those applications to academic classes may be no good, but those to literacy classes and remedial study classes may be good. For example, applications of the 'Microsoft Office Specialist (MOS)' and 'Nissho Personal Computer test' to information literacy classes are considered to be good. Here is a correspondence table of classes in L.A. and qualifying exams.

Table 1: Classes in liberal arts and qualifying exams

\begin{tabular}{|l|l|}
\hline \multicolumn{1}{|c|}{ Class titles } & \multicolumn{1}{c|}{ Corresponding exams } \\
\hline Information literacy & Nissho Personal Computer test [13] \\
\hline Information literacy & MOS [14] \\
\hline Information literacy & Japanese word-processing skill standard test [15] \\
\hline Information literacy & Spreadsheet skill standard test [15] \\
\hline Basic book keeping & Nissho bookkeeping test [16] \\
\hline First-year experience & Secretary test, Business practice test [17] \\
\hline Basic English & TOEFL [18] \\
\hline Basic English & TOEIC [19] \\
\hline Basic English & Eiken test [20] \\
\hline Financial literacy & AFP [21] \\
\hline Career design & FP skill test [22] \\
\hline
\end{tabular}

There are a lot of qualifying exams for proving PC skills. Here, Nissho Personal Computer test as an official exam, MOS as a de facto standard exam, and Japanese word-processing and spreadsheet skill standard test which are used in our information literacy classes are shown. Since contents of these exams are versatile, these may be used in information literacy classes at many universities. Nissho bookkeeping test as an official exam is selected for Basic bookkeeping class. Zensho bookkeeping test as an official exam [23] is provided for high school bookkeeping classes by ZENSHO. This is the case that quality assurance of education using qualifying exams is performed by the official support. The TOEFL, TOEIC, and Eiken are useful official tools for Basic English classes. The AFP and FP skill tests are for financial 
literacy or career design classes. In 2011, Japanese law of university establishment made the career education compulsory in university classes [24] and since then the career design classes started to be offered in many universities. The content of career designs includes financial literacy. Judging from the above, these exams are useful tools for those classes.

\subsection{Ease of management for multiple classes}

In L.A. classes, the classes may be offered in multiple ways, and their instructors are full-time or part-time. Even if an instructor is part-time, he should offer the same quality education as a full-time instructor. In order to achieve the duty, full-time instructors who are in charge of those classes should plan and prepare those contents, and should explain them to other instructors.

Actually, the author was responsible for that task in information literacy classes. Though much time and effort had been devoted to achieve the task, there is still much anxiety about my content for the classes. Therefore we decided to use the 'Japanese word-processing skill standard test' and 'Spreadsheet skill standard test' for quality assurance in the classes. By taking advantages of using these exams, the classes can be planned without loss of generality and it became easy for other instructors to understand the plan via HP [15] or past exams. This detail is following.

The case of using these qualifying exams in information literacy classes for quality assurance is reported [25]. The target classes are 'Information literacy 1 (First year, spring, 2-units)' and 'Information literacy 2 (First year, autumn, 2-units)'. The management of those classes is as follows:

- Distribution of tuition (Class schedules, evaluation criteria and so on)

- Creating texts (Noa publish) [26]

(1)Office drill text consisting of 555 problems

(2)Past exams of Japanese word-processer skill standard test

(3)Past exams of spreadsheet skill standard test

- Distribution of prints (quizzes and final exams)

- Qualifying exams [15]

(1)Japanese word-processer skill standard test

(Information literacy 1)

(2)Spreadsheet skill standard test

(Information literacy 2)

\subsection{Encouraging students' learning motivation}

As described in Sec. 4, it is clear that university students' motivation for licenses or qualifying exams is high, and the application of exams to classes in universities is useful. It can be easily expected that students' learning motivation in classes on information literacy, remedial education, and first-year experience shows a downward tendency because the students studied these contents only once in a course of the subject. Therefore, the author also aims at providing further incentives to them as well as quality assurance for classes.

\section{Learning motivation generated by qualifying exams}

\subsection{Application to the classes in information literacy}

Recently, it is often said that basic literacy ability of university students at enrollment becomes lower and lower $[1,27,28]$. In consequence, in many universities remedial and literacy edu-cation has been carried in various ways. Although there has been an image that remedial or literacy education is the review of high school subjects, now the one of junior high school subjects is carried out in some universities now because of students' basic literacy ability falling.

Information literacy got to be included in course of study on elementary and secondary education [2], but a lot of university students don't have basic ability on information literacy 
as well as math, Japanese, English and so on. It may seem to be a mistake that we assume students have already mastered those subjects before their entrance in university because PCs are popular in almost every home in Japan. In fact, according to previous survey for almost all freshmen belonging to the department of psychology and child studies (the valid response 72 of 76) at a college in 2007 [29], the results are as follows:

- Data can be saved : $71 \%$

- Files or folders can be created : $49 \%$

- Bulleted lists can be written with WORD : $33 \%$

- Tables can be created and edited with WORD :29\%

The more information technology becomes popular in society, the more information literacy education is carried out at school. Almost all students can use internet or mobile e-mail accordingly. They, however, do not necessarily have the information literacy and PC skill. It is presumed that these university students aren't happy to learn the information literacy again. It is necessary for them to repeat learning for getting basic PC skill. They seem to dislike to study according to this survey. So, it is difficult for them to study information literacy again.

The author has carried out a class using the qualifying exams [15] and measured the effect on this problem. We made the documentation sets described in Sec. 3.2 available to any university or college instructors. The contents and topics of Japanese word-processing 3-grade test are shown in the website [15]. The tuition plans are created based on these contents.

The questionnaire survey is conducted for all first grade students belonging to the department of psychology and child studies at the college in 2007 (the valid response 72 for 76) and 2008 (the valid response 38 for 42). The analyzed classes are all 'Information literacy 1' and 'Information literacy 2' which are compulsory and are taught by a full-time associate professor and part-time instructors. The questionnaires about their skill and experience on PC, and motivation for studying are asked at the beginning and the end of the classes. The comparative analysis between the classes with qualifying exams in 2007 and the ones without them in 2008 is performed.

They study how to operate the Windows and the Word in Information literacy 1, and how to operate the Excel in Information literacy 2.

The survey result of their experience and skill on PC at the first lecture in Information literacy 1 is shown in Table 2 .

Table 2: Comparison of skill and experience on PC

\begin{tabular}{|c|l|c|c|}
\hline \multicolumn{2}{|c|}{ Questionnaire } & \multicolumn{2}{c|}{ Rate of Yes } \\
\cline { 3 - 4 } & \multicolumn{1}{|c|}{2007} & 2008 \\
\hline \multirow{5}{*}{ Experience } & Operating PC & $97 \%$ & $100 \%$ \\
\cline { 2 - 4 } & Using internet & $96 \%$ & $98 \%$ \\
\cline { 2 - 4 } & Having information literacy class at high school & $96 \%$ & $90 \%$ \\
\cline { 2 - 4 } & Operating Word & $83 \%$ & $85 \%$ \\
\cline { 2 - 4 } & Operating Excel & $71 \%$ & $73 \%$ \\
\hline \multirow{5}{*}{ Basic skill } & Input characters with PC & $92 \%$ & $95 \%$ \\
\cline { 2 - 4 } & Saving data & $71 \%$ & $73 \%$ \\
\cline { 2 - 4 } & Creating folder & $49 \%$ & $44 \%$ \\
\cline { 2 - 4 } & Copying file & $53 \%$ & $46 \%$ \\
\hline \multirow{3}{*}{ Word skill } & Writing bullet point & $33 \%$ & $32 \%$ \\
\cline { 2 - 4 } & Creating table & $29 \%$ & $20 \%$ \\
\hline & Using arithmetic four operations & $21 \%$ & $17 \%$ \\
\cline { 2 - 4 } & Operating function & $15 \%$ & $10 \%$ \\
\cline { 2 - 4 } & Editing table & $28 \%$ & $15 \%$ \\
\cline { 2 - 4 } & Creating and Editing graph & $78 \%$ & $7 \%$ \\
\hline
\end{tabular}

This data is statistically tested, and it is confirmed that there is no significant difference between the two universes, the students in 2007 and the ones in 2008. It is concluded that there is no difference to the quality between them. 
The more survey results of motivation on studying information literacy at the last lecture in Information literacy 1 and Information literacy 2 are shown in Tables 3-5.

Table 3: Questionnaire at the last lecture in information literacy 1

\begin{tabular}{|l|l|}
\hline & \multicolumn{1}{c|}{ Questionnaire } \\
\hline \multirow{3}{*}{ Motivation } & $\begin{array}{l}\text { (1)Attending class } \\
\text { (2)Studying prospectively and seriously } \\
\text { (3)Improving skill } \\
\text { (4)Understanding how to operate the Word } \\
\text { (5)Desiring to take more exams }\end{array}$ \\
\hline
\end{tabular}

Table 4: Questionnaire at the last lecture in information literacy 2

\begin{tabular}{|l|l|}
\hline & \multicolumn{1}{c|}{ Questionnaire } \\
\hline \multirow{5}{*}{ Motivation } & (6)Attending class \\
& (7)Studying prospectively and seriously \\
& (8)Improving skill \\
& (9)Desiring to take more exams \\
(10)Desiring to take advanced courses
\end{tabular}

Table 5: Statistically test 1 (Rate of Yes)

\begin{tabular}{|c|r|r|r|r|r|r|r|r|r|r|}
\hline & \multicolumn{1}{|c|}{$(1)$} & \multicolumn{1}{|c|}{$(2)$} & \multicolumn{1}{c|}{$(3)$} & \multicolumn{1}{c|}{$(4)$} & \multicolumn{1}{c|}{$(5)$} & \multicolumn{1}{c|}{$(6)$} & \multicolumn{1}{c|}{$(7)$} & \multicolumn{1}{c|}{$(8)$} & \multicolumn{1}{c|}{$(9)$} & \multicolumn{1}{c|}{$(10)$} \\
\hline 2007 & $86.1 \%$ & $97.2 \%$ & $94.4 \%$ & $93.1 \%$ & $95.8 \%$ & $86.6 \%$ & $98.5 \%$ & $91.0 \%$ & $82.1 \%$ & $35.8 \%$ \\
\hline 2008 & $96.7 \%$ & $94.7 \%$ & $78.9 \%$ & $86.8 \%$ & $60.5 \%$ & $78.0 \%$ & $92.7 \%$ & $85.4 \%$ & $61.0 \%$ & $14.6 \%$ \\
\hline T value & -1.38 & 0.66 & $\mathbf{2 . 4 7}$ & 1.08 & $\mathbf{4 . 7 6}$ & 1.15 & 1.53 & 0.90 & $\mathbf{2 . 4 0}$ & $\mathbf{2 . 3 6}$ \\
\hline
\end{tabular}

To summarize the above results, it is found that the learning effect is enhanced by use of the qualifying exams as follows $(\mathrm{p}<0.05)$.

- (3)PC skill is improved ( $\mathrm{T}=2.47)$.

- (5), (9) They want to take more exams $(\mathrm{T}=4.76,2.40)$.

- (10)They hope to take advanced courses $(\mathrm{T}=2.36)$.

In addition, the followings cannot be concluded in statistics, but are numerical facts.

- (2),(7)They study prospectively and seriously $(\mathrm{T}=0.66,1.53)$.

- (4)They understand how to operate the Word $(\mathrm{T}=1.08)$.

- (8)PC skill is improved $(\mathrm{T}=0.90)$.

Then, it is concluded that the students who took classes with qualifying exams proved their PC skill more than ones without the exams, and after taking the exams, they became to desire to take more exams and advanced courses.

In this section, it is confirmed that the application of qualifying exams to 'Information literacy' classes in university is useful in this universe or equivalent ones for encouraging motivation.

\subsection{Application of using qualifying exams to the classes in other generic or special subjects}

In previous subsection, it became clear that the application of using qualifying exams only to the information literacy classes is useful. The more straightforward questionnaire survey on application to other generic or special subjects is performed [21].

This is carried out for all freshmen (the valid response 63 of 77), at the college in 2011 when the classes finish. The questionnaire and the result are shown in Table 6. 
Table 6: Questionnaire survey about application of qualifying exams to other generic or spe-

cial subjects

\begin{tabular}{|l|c|c|}
\hline \multicolumn{1}{|c|}{ Questionnaire } & $\begin{array}{c}\text { Average } \\
\text { score }\end{array}$ & Rate of Yes \\
\hline (1)Studying in the class, 'Information literacy 1' diligently & 4.3 & $82 \%$ \\
\hline (2)Being motivated by qualifying exams in this class & 4.6 & $95 \%$ \\
\hline $\begin{array}{l}\text { (3)Being motivated by qualifying exams in other generic or } \\
\text { special subjects }\end{array}$ & 4.2 & $82 \%$ \\
\hline
\end{tabular}

The score are as follows (score):

'Yes (5)', 'Somewhat Yes (4)', 'Neither (3)', 'Somewhat No (2)' and 'No (1)'.

It is confirmed that application of exams to classes, 'Information literacy 1 ' is also useful for the students in 2011 from the result of questionnaire (1). Further, it should be noted that there is positive correlation between studying diligently (1) and their motivation (2). The correlation coefficient is 0.78 . Then, we can confirm the effect of encouraging motivation by the aid of qualifying exams again.

In addition, application of using qualifying exams to other subjects is supported by $82 \%$ students and their average score is 4.2 .

Then it may conclude that application to the other subjects is useful.

\section{Desire for taking license or qualifying exam}

In this section, the questionnaire survey on university students' desire for acquiring licenses (including exams) is reported.

This is carried out for all freshmen (the valid response 66 of 80), at the college in 2010[30]. The results are as follows:

- The $83 \%$ students want to acquire licenses or pass qualifying exams.

- The reason why they want to acquire licenses and pass qualifying exams is to get jobs.

- They want to have 3.6 (average) licenses or pass qualifying exams.

- Their selection of a university depends on whether the courses for licenses and qualifying exams are provided or not.

- Their important criteria for selecting universities are licenses, getting jobs, and majors.

Hence, it can be suggested that a lot of high school students want to acquire licenses or pass qualifying exams because they are worried about getting jobs, and they select universities in which the courses to acquire licenses and pass qualifying exams are provided (Figure 1).

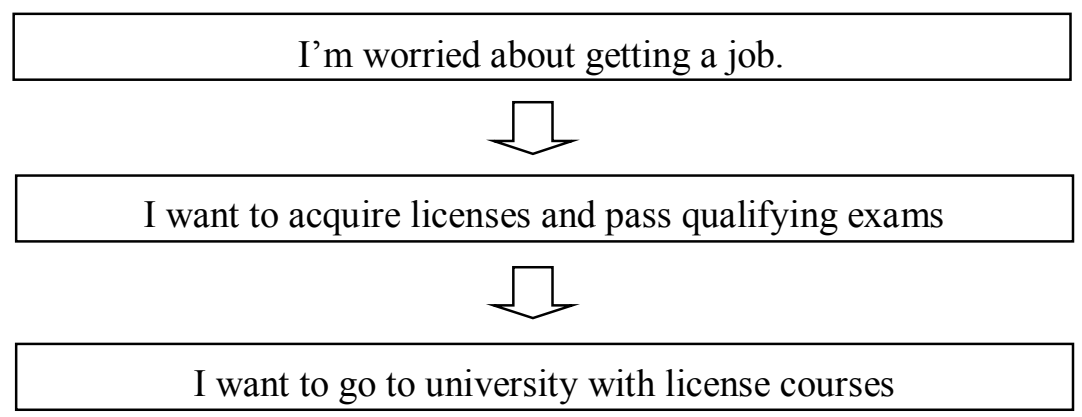

Figure 1: The status of students

Because there are a lot of students who want to take licenses or qualifying exams, the application of using these to university classes is significant for universities in view of acquiring students as well as quality assurance for their education. Consequently, it is necessary for university instructors or professors to have comprehensive knowledge of licenses and 
qualifying exams, and to teach it to their students. The education about licenses and qualify-ing exams should be naturally integrated in career education which has been compulsory in the law of university establishment since 2011 [24].

\section{Summary}

In this study, we considered using qualifying exams for quality assurance of education content and evaluation of study in university classes. There are three merits in using them: 'Clarify of goals and evaluation criteria', 'Ease of management for multiple classes', and 'Encouraging students' learning motivation'. The first two can be easily understood with our examples in information literacy classes. The last one is confirmed by the previous questionnaire surveys. Then, it is obvious that a lot of students want to go to universities with license or qualifying exam courses.

It is summarized that the application of using qualifying exams are useful for management of multiple classes and quality assurance in university education and acquiring students in university administration.

\section{References}

[1] Central Council for Education report, "Toward construction of undergraduate education, " 2008, p.1

[2] Ministry of Education, Culture, Sports, Science, "New course of study," May 2012, http:/www.mext.go.jp/a_menu/shotou/new-cs/youryou/index.htm.

[3] S. Nihei, "Notes on the concept of organizing definition about license and qualifying exam at teaching," Proceedings of the 27th Convention of Japan Society of Applied Business Studies, 2007,pp.77-79.

[4] I. Komatsu, "Survey on teaching to acquire licenses or qualifying exams at universities and junior colleges in Japan," 2003, National Institute of Educational Policy Reserch.

[5] S. Kohno, "Classifying licenses and qualifying exams, and significance of obtaining them for students in private universities," Reserch paper of survey on construction of correlation system between universities and industrial society, 2006, pp.79-101, National Institute of Educational Policy Reserch.

[6] Y. Namatame, "Results of a Survey on Obtaining Qualifications for Business skill," 2000, Komatsu junior college Review, 12, pp.13-26.

[7] Ministry of Education, Culture, Sports, Science, "Summary of education between high school and university," 2008, http://www.mext.go.jp/b_menu/shingi/chukyo/chukyo3/siryo/08030317/002.htm.

[8] A. Kannon, "Center publications introduce 'Remedial education of the University" 1997, Hiroshima University Center for Education and Research, University Journal, p.197.

[9] M. Sawada, "Efforts in the transition and Prospects and the University of Remedial Education" 2014, Kobe Kaisei College Research Grant report, pp.42-44.

[10] Japan Remedial Education Society, "Current Status and Problems of challenge -Remedial education for learning support in the University"2012, p.255.

[11] K.Higuchi, "Rating on the package of information literacy education" ,2011 fiscal ICT Promotion Council Annual Meeting Proceedings, pp113-119. 
[12] M.Hirano, "Similarities between Basic English Educationand Information Literacy Education in General Education in Japanese Universities"2013, JACET the 52th international convention Abstruct, p.61.

[13] Chamber of Commerce and Industry of Japan, "Nissho PC test," May 2012, http://www.kentei.ne.jp/pc/.

[14] Odyssey, "MOS Official Site," May 2012, http://mos.odyssey-com.co.jp/index.html.

[15] Noa Inc, "Personal Computer skill standard tests," May 2012, http://www.noa-prolab.co.jp/shp/examination/index.html.

[16] Chamber of Commerce and Industry of Japan, "Nissho bookkeeping test," May 2012, http://www.kentei.ne.jp/bookkeeping/.

[17] Association of practical skills test, "Buisiness tests," May 2012, http://jitsumu-kentei.jp/.

[18] CIEE, "TOEFL test," May 2012, http://www.cieej.or.jp/toefl/.

[19] IIBC, "Official site of TOEIC," May 2012, http://www.toeic.or.jp/.

[20] Association of Eiken test, "Eiken," May 2012, http://www.eiken.or.jp/eiken.html.

[21] JAFP, "Test information of FP," May 2012, http://www.jafp.or.jp/examine/.

[22] KINZAI, "Skills Test of FP," May 2012, http://www.kinzai.or.jp/ginou/fp/index.html.

[23]ZENSHO, "Bookkeeping test," 2012, http://www.zensho.or.jp/puf/examination/bookkeeping.html.

[24] Prime Minister of Japan and His cabinet, "Progress of carrer guidance in higher education," May 2012,

http:/www.kantei.go.jp/jp/singi/kinkyukoyou/pdf/02_careerguidance.pdf.

[25] K. Higuchi,"Benet of the packaging in information literacy class using qualifying exams to progress student's learning motivation," 2011, Proc. of Annual Meeting of the University Council for ICT in 2011, pp.218-219.

[26] Noa Inc, "Schooling texts," May 2012, http://www.noa-prolab.co.jp/shp/index.html

[27] K. Nishimura edi, "University students who cannot solve fraction calculations, " 1999, Toyo keizai sinpousha.

[28] K. Higuchi, "Study on the understanding of the percentage of university students," Proc. of convention in Japan Mathematical Education Society in 2005, pp.795-796.

[29] K. Higuchi, "The study of encouraging student's learning motivation using qualify exams in information literacy classes," Proc. of the 28th Convention in 2009, Japan Society of Applied Business Studies, pp.59-60.

[30] K. Higuchi, "The survey of university students' attitude on licenses and qualifying exams," Proc. of the 30th Convention in 2011, Japan Society of Applied Business Studies, pp.66-69. 